\title{
SUMMARY OF 1984 WHOOPING CRANE STUDIES
}

E. KUYT and J. PAUL GOOSSEN, Canadian Wildlife Service, \# 1000, 9942-108th Street, Edmonton, Alberta. T5K 2J5

The annual winter inventory of Whooping Cranes on the Aransas National Wildlife Refuge near Corpus Christi, Texas had not been completed, and although it is possible that one or two birds may have been overlooked or have not yet arrived, for practical purposes the entire Wood Buffalo National Park population had completed its fall migration and was in its winter residence.

The results of aerial surveys carried out by refuge biologist T. Stehn have confirmed September 1984 Canadian Wildlife Service reports stating that a record crane population, including 13-15 chicks, was expected to reach the Texas coast. Late December and early January counts at Aransas indicate a population of 84 birds (75 in 1983), including 15 chicks (7 in 1983). The previous high was established in 1980 when 78 birds wintered at Aransas. The juvenile complement of 15 birds surpasses the former record of 12 chicks set in 1976 .

Canadian Wildlife Service surveys over the breeding range in Wood Buffalo National Park in 1984 located 29 nests, all but one containing the customary clutch of two eggs. On 21 and 23 May we removed 25 surplus eggs and transferred these to the Grays Lake National Wildlife Refuge in Idaho where 22 of the eggs were placed in nests of Greater Sandhill Cranes. Before shipment from Fort Smith, N.W.T., we tested all collected eggs (about one week from hatching) by means of flotation and found that only two eggs showed no evidence of life. These two eggs and a third live egg were shipped to the Patuxent Wildlife Research Centre near Laurel, Maryland, for analysis of the dead eggs. The live egg hatched and the chick was added to the captive whooper population which now numbers about 35 birds. Of the 22 eggs placed in sandhill nests in Idaho, 19 hatched and 10 chicks eventually flew from the Grays Lake Refuge. About 35 Whooping Cranes make up that population which winters on or near the Bosque del Apache National Wildlife Refuge in New Mexico. Pairing of birds in that population has been observed a few times but prolonged associations have not yet occurred.

After the removal of the 25 surplus eggs, 32 eggs remained in nests in Wood Buffalo National Park. Two eggs laid by an early nester hatched on or about the day of pickup and the last three nests with full clutches were not visited because of failure of the pick-up helicopter's engine. The prolonged stay of the damaged helicopter near one nest discouraged the incubating bird and forced us to remove both eggs. Two of the four pairs whose nests were not visited hatched both their eggs but sometime between June and late July each pair lost one of its young. Both pairs are now in Texas with their chicks. The two eggs in the third nest not visited were missing during an aerial survey after the egg pick-up and aerial observations near the fourth nest indicated that the two eggs or chicks were lost between 23 May and 5 June 1984, perhaps as a result of predation.

Of 24 single eggs remaining in Wood Buffalo National Park after the pick-up, 21 are known to have hatched. Two addled eggs were collected on 6 and 21 June. On the latter date 20 chicks were still alive. Only a single chick is known to have died between 21 June and 31 July and a second chick may have disappeared shortly thereafter. On 4 August we captured and 
colour-banded 13 of 18 chicks known to be in the area. Ten of the banded chicks and five unbanded ones are currently on the winter range. One of the missing colourbanded juveniles was seen in Wood Buffalo National Park as late as 11 September, when it should have been capable of flight and safe from terrestrial predators.

The large number of chicks produced in 1984 is a direct result of recent increases in the breeding population combined with improved habitat conditions in 1983 and 1984. Satisfactory survival of colour-banded juveniles from 1977-1979 (and perhaps from the 1976 cohort) have resulted in these birds "graduating" to the breeding segment of the population. This has resulted in increases of 26 and 21 percent in the number of breeding pairs in the last 2 years to the current 29 pairs.

Over the years to come, the reported sighting of colour-banded birds will contribute immensely to our understanding of distribution, migration, habitat selection, nest site fidelity and many other factors important to the continuation of our cooperative efforts in Whooping Crane conservation.

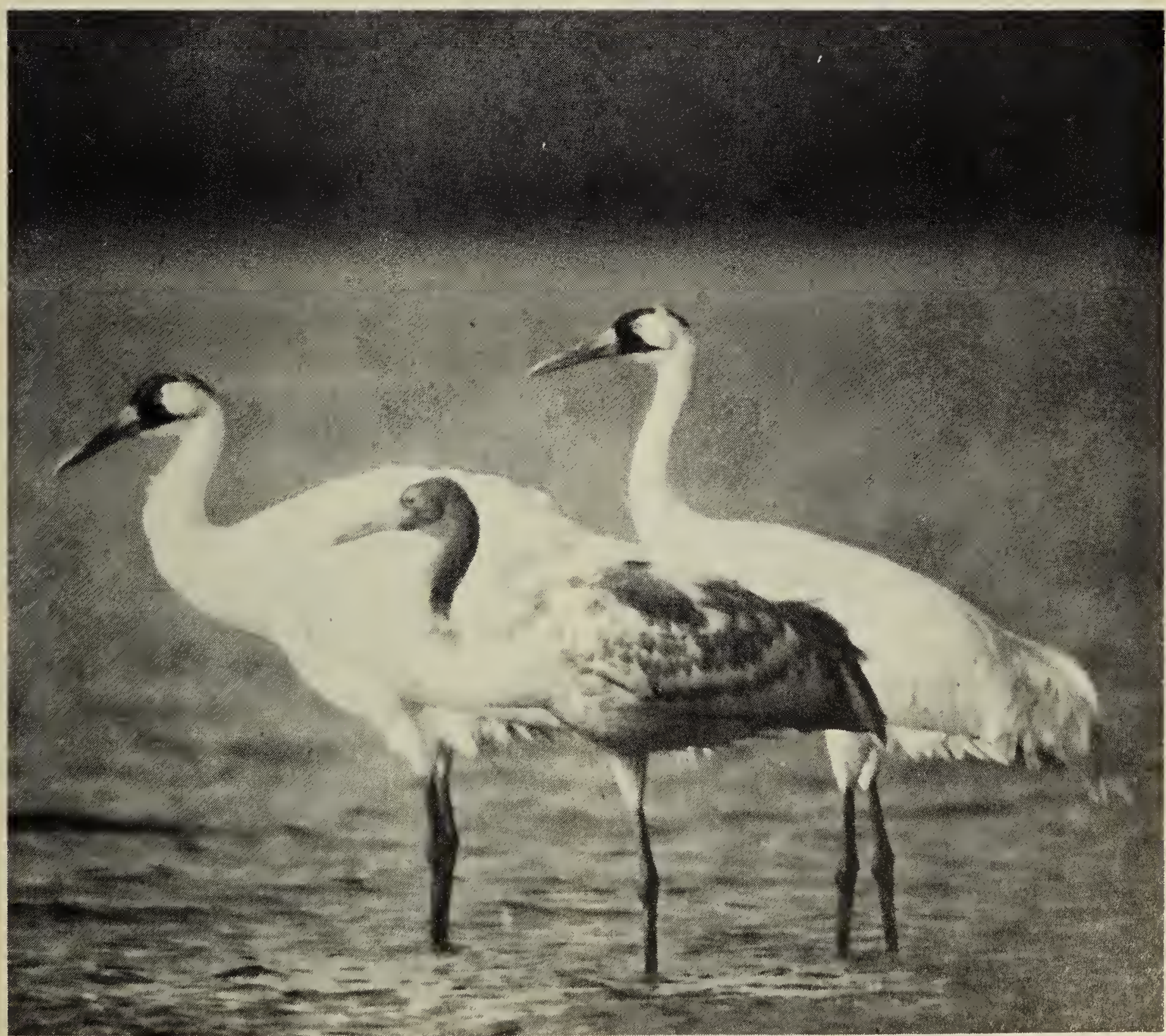

